\title{
Weiterbildungskurse in Ungarn
}

Die Kurse in Ungarn erfreuen sich einer wachsenden Beliebtheit. Zusätzliche Kurse werden deshalb schon in diesem Jahr noch ins Programm aufgenommen. Die Supervisions- und Intensiv-Trainingskurse mit nur maximal 4-6 Teilnehmern füllen eine Marktlücke. Neben der Theorie und Praxis im Gebiet des Ultraschalls kommt aber auch die Freizeit nicht zu kurz. Neu steht ab April im Kurszentrum sogar ein echter Flugsimulator, für Abwechslung ist also gesorgt... Alle Einzelheiten hierzu sind im Internet aufgeschaltet unter www.ungarnkurse.info

\section{Beat Dubs}

\begin{tabular}{|c|c|c|}
\hline \multicolumn{3}{|c|}{$\begin{array}{l}\text { Ultraschall-Kursangebot in Ungarn im Jahr } 2015 \\
\text { Ort: Csipkerozsa-Park, H } 6135 \text { Csòlyospàlos } \\
\text { Alle Einzelheiten und aktuelle Hinweise auf www.ungarnkurse.ch }\end{array}$} \\
\hline Datum & Kursbezeichnung & Kursleiter \\
\hline $\begin{array}{l}\text { Do } 07.05 .- \text { So } \\
10.05 .2015\end{array}$ & $\begin{array}{l}\text { Intensiv-Trainingskurs 6/2015 Abdomen, Weichteile } \\
\text { und Bewegungsapparat }\end{array}$ & Dr. Beat Dubs \\
\hline $\begin{array}{l}\text { Do } 28.05 .- \text { So } \\
31.05 .2015\end{array}$ & $\begin{array}{l}\text { Intensiv-Trainingskurs 7/2015 Abdomen, Weichteile } \\
\text { und Bewegungsapparat }\end{array}$ & Dr. Beat Dubs \\
\hline $\begin{array}{l}\text { Do } 11.06 .- \text { So } \\
14.06 .2015\end{array}$ & $\begin{array}{l}\text { Intensiv-Trainingskurs 8/2015 Abdomen, Weichteile } \\
\text { und Bewegungsapparat }\end{array}$ & Dr. Beat Dubs \\
\hline $\begin{array}{l}\text { Fr 12.06. - So } \\
14.06 .2015\end{array}$ & Refresherkurs Sonografie der Säuglingshüfte & Dr. Markus Renggli \\
\hline $\begin{array}{l}\text { Do } 25.06 .- \text { So } \\
28.06 .2015\end{array}$ & $\begin{array}{l}\text { Grundkurs } 1 / 2015 \text { Sonografie des Bewegungsapparates } \\
\text { (nach SGUM Richtlinien) }\end{array}$ & Dr. Beat Dubs \\
\hline $\begin{array}{l}\text { So } 05.07 .- \text { So } \\
12.07 .2015\end{array}$ & $\begin{array}{l}\text { Intensiv-Trainings-Wochenkurs 9/2015 Weichteile und } \\
\text { Bewegungsapparat }\end{array}$ & Dr. Beat Dubs \\
\hline $\begin{array}{l}\text { Mo 03.08.-So } \\
09.08 .2015\end{array}$ & $\begin{array}{l}\text { „Sono-Ferien“ mit massgeschneiderten Sonografie-Lek- } \\
\text { tionen (Weichteile und Bewegungsapparat) }\end{array}$ & Dr. Beat Dubs \\
\hline $\begin{array}{l}\text { Do } 27.08 .- \text { So } \\
30.08 .2015\end{array}$ & $\begin{array}{l}\text { Intensiv-Trainingskurs 10/2015 Abdomen, Weichteile } \\
\text { und Bewegungsapparat }\end{array}$ & Dr. Beat Dubs \\
\hline $\begin{array}{l}\text { Do } 10.09 .- \text { So } \\
\text { 13.09.2015 }\end{array}$ & $\begin{array}{l}\text { Expertenkurs Sonografie des Bewegungsapparates inkl. } \\
\text { Inguinalregion }\end{array}$ & Dr. Beat Dubs \\
\hline $\begin{array}{l}\text { Do } 17.09 .- \text { So } \\
20.09 .2015\end{array}$ & $\begin{array}{l}\text { Grundkurs 2/2015 Sonografie des Bewegungs-appara- } \\
\text { tes (nach SGUM Richtlinien) }\end{array}$ & Dr. Beat Dubs \\
\hline $\begin{array}{l}\text { So } 27.09 .- \text { So } \\
04.10 .2015\end{array}$ & $\begin{array}{l}\text { Intensiv-Trainings-Wochenkurs 11/2015 Weichteile und } \\
\text { Bewegungsapparat }\end{array}$ & Dr. Beat Dubs \\
\hline $\begin{array}{l}\text { Di 13.10. - Do } \\
\text { 15.10.2015 }\end{array}$ & Refresherkurs Sonografie der Säuglingshüfte & $\begin{array}{l}\text { Dr. Beat Dubs } \\
\text { Dr. Gertrud Remsei }\end{array}$ \\
\hline $\begin{array}{l}\text { Do } 29.10 .- \text { So } \\
01.11 .2015\end{array}$ & $\begin{array}{l}\text { Intensiv-Trainingskurs 12/2015 Abdomen, Weichteile } \\
\text { und Bewegungsapparat }\end{array}$ & Dr. Beat Dubs \\
\hline $\begin{array}{l}\text { Do } 19.11 .- \text { So } \\
22.11 .2015\end{array}$ & $\begin{array}{l}\text { Intensiv-Trainingskurs 13/2015 Abdomen, Weichteile } \\
\text { und Bewegungsapparat }\end{array}$ & Dr. Beat Dubs \\
\hline
\end{tabular}

Weitere Kurse nach Bedarf, siehe jeweils www.ungarnkurse.ch 